\title{
The differential impact of intraventricular and interventricular dyssynchrony on left ventricular remodeling and function in patients with isolated left bundle branch block
}

\author{
Valentina Valenti ${ }^{1,2^{*}}$, Mohammad I Zia ${ }^{1,4}$, Azhar Supariwala ${ }^{3}$, Leon Shubayev ${ }^{1}$, Sophia Edelstein ${ }^{1}$, Matt Levin ${ }^{1}$, \\ Seth Uretsky ${ }^{1,3}$, Steven D Wolff ${ }^{1}$
}

From 15th Annual SCMR Scientific Sessions

Orlando, FL, USA. 2-5 February 2012

\section{Summary}

Interventricular dyssynchrony evaluated with cardiac magnetic resonance is an independent predictor of systolic dysfunction and left ventricular remodeling while intraventricular dyssynchrony is an independent predictor of LV diastolic dysfunction in patients with isolated LBBB. Comprehensive evaluation of both these parameters of dyssynchrony would be useful in selecting patients for cardiac resynchronization therapy.

\section{Background}

Dyssynchrony in patients with left bundle branch block (LBBB) plays an important role in the development of left ventricular (LV) dilation, systolic dysfunction, progression of heart failure and mortality. Intraventricular dyssynchrony (IntraVD) and interventricular dyssynchrony (InterVD) may have different impacts on myocardial structure and function in patients with LBBB. Our objective was to characterize the independent effects of IntraVD and InterVD on myocardial structure and performance.

\section{Methods}

Thirty-two patients with isolated LBBB (15 males, mean age: 61 years \pm 13 ) were assessed using cardiac magnetic resonance imaging. IntraVD was defined as the difference between the time of maximum systolic wall thickness of the septum and lateral wall of the left ventricle. InterVD was defined as the time difference between the

${ }^{1}$ Advanced Cardiovascular Imaging, New York, NY, USA

Full list of author information is available at the end of the article onset of pulmonic and aortic flow. Peak filling rate (PFR) and time to peak filling rate (TPFR) were measured as surrogates of diastolic function.

\section{Results}

InterVD had a moderate inverse negative correlation with LV ejection fraction $(\mathrm{r} 2=-0.5)$, and a moderate positive correlation with LV end-diastolic volume index (LVEDVI) (r2=0.4) and LV end-systolic volume index (LVESVI) (r2=0.5). The IntraVD had no significant correlation with LV remodeling and function parameters. Multivariate analysis also demonstrated that InterVD was an independent predictor of left ventricular systolic dysfunction $(\mathrm{p}<0.0001)$, increased LVEDVI $(\mathrm{p}<0.01)$, and increased LVESVI $(\mathrm{P}<0.001)$.

In terms of diastolic dysfunction, IntraVD had a moderate positive correlation with THFR $(\mathrm{r} 2=0.5)$ and moderate negative correlation with PFR $(\mathrm{r} 2=-0.5)$. InterVD was not significantly correlated with any diastolic dysfunction parameter. Multivariate analysis confirmed that IntraVD was an independent predictor of left ventricular diastolic dysfunction (PFR: $\mathrm{p}<0.001$; TPFR: $\mathrm{p}<0001$ ).

\section{Conclusions}

InterVD evaluated with CMR is an independent predictor of systolic dysfunction and left ventricular remodeling. IntraVD evaluated with CMR is an independent predictor of LV diastolic dysfunction. A comprehensive evaluation of both these independent measures of dyssynchrony could be helpful in improving the patient selection algorithm for cardiac resynchronization therapy. 


\section{Funding}

None.

\section{Author details}

${ }^{1}$ Advanced Cardiovascular Imaging, New York, NY, USA. ${ }^{2}$ Radiology,

University "La Sapienza," Sant'Andrea Hospital, Rome, Italy. ${ }^{3}$ Medicine, St.

Luke's Roosevelt Hospital Centre, New York, NY, USA. ${ }^{4}$ Sunnybrook Health

Sciences Centre, Toronto, ON, Canada.

Published: 1 February 2012

doi:10.1186/1532-429X-14-S1-P149

Cite this article as: Valenti et al:: The differential impact of

intraventricular and interventricular dyssynchrony on left ventricular

remodeling and function in patients with isolated left bundle branch

block. Journal of Cardiovascular Magnetic Resonance 2012 14(Suppl 1):P149.

Submit your next manuscript to BioMed Central and take full advantage of:

- Convenient online submission

- Thorough peer review

- No space constraints or color figure charges

- Immediate publication on acceptance

- Inclusion in PubMed, CAS, Scopus and Google Scholar

- Research which is freely available for redistribution

Submit your manuscript at www.biomedcentral.com/submit 